\title{
Article \\ Genetic and Pharmacological Inhibition of Autophagy Increases the Monoubiquitination of Non-Photosynthetic Phosphoenolpyruvate Carboxylase
}

\author{
Guillermo Baena (D), Ana B. Feria, Luis Hernández-Huertas, Jacinto Gandullo, Cristina Echevarría, José A. Monreal \\ and Sofía García-Mauriño *(D)
}

check for

updates

Citation: Baena, G.; Feria, A.B.; Hernández-Huertas, L.; Gandullo, J.; Echevarría, C.; Monreal, J.A.; García-Mauriño, S. Genetic and Pharmacological Inhibition of Autophagy Increases the Monoubiquitination of Non-Photosynthetic Phosphoenolpyruvate Carboxylase. Plants 2021, 10, 12. https:/ /dx.doi. org/10.3390/plants10010012

Received: 23 November 2020 Accepted: 22 December 2020 Published: 23 December 2020

Publisher's Note: MDPI stays neutral with regard to jurisdictional claims in published maps and institutional affiliations.

Copyright: (C) 2020 by the authors. Licensee MDPI, Basel, Switzerland. This article is an open access article distributed under the terms and conditions of the Creative Commons Attribution (CC BY) license (https: / / creativecommons.org/ licenses/by/4.0/).
Departamento de Biología Vegetal y Ecología, Facultad de Biología, Universidad de Sevilla, Avenida Reina Mercedes nº, 41012 Seville, Spain; gbaena@us.es (G.B.); anabelen@us.es (A.B.F.); luishernanhuertas@gmail.com (L.H.-H.); jacintogt@us.es (J.G.); echeva@us.es (C.E.); monreal@us.es (J.A.M.)

* Correspondence: sgarma@us.es

Abstract: Phosphoenolpyruvate carboxylase (PEPC) is an enzyme with key roles in carbon and nitrogen metabolisms. The mechanisms that control enzyme stability and turnover are not well known. This paper investigates the degradation of PEPC via selective autophagy, including the role of the monoubiquitination of the enzyme in this process. In Arabidopsis, the genetic inhibition of autophagy increases the amount of monoubiquitinated PEPC in the atg2, atg5, and atg18a lines. The same is observed in $n b r 1$, which is deficient in a protein that recruits monoubiquitinated substrates for selective autophagy. In cultured tobacco cells, the chemical inhibition of the degradation of autophagic substrates increases the quantity of PEPC proteins. When the formation of the autophagosome is blocked with 3-methyladenine (3-MA), monoubiquitinated PEPC accumulates as a result. Finally, pull-down experiments with a truncated version of NBR1 demonstrate the recovery of intact and/or fragmented PEPC in Arabidopsis leaves and roots, as well as cultured tobacco cells. Taken together, the results show that a fraction of PEPC is cleaved via selective autophagy and that the monoubiquitination of the enzyme has a role in its recruitment towards this pathway. Although autophagy seems to be a minor pathway, the results presented here increase the knowledge about the role of monoubiquitination and the regulation of PEPC degradation.

Keywords: autophagy; Arabidopsis thaliana; Nicotiana benthamiana; phosphoenolpyruvate carboxylase; ubiquitin

\section{Introduction}

Phosphoenolpyruvate carboxylase (PEPC; EC 4.1.1.31) is a key enzyme in the metabolism of carbon $(\mathrm{C})$ and nitrogen $(\mathrm{N})$, with central roles in photosynthesis, respiration, amino acid synthesis, and the development and germination of seeds [1,2]. This enzyme catalyzes the addition of bicarbonate to PEP to form the four-carbon compound oxaloacetate, which is reduced to malate by malate dehydrogenase (MDH). PEPC is mostly acknowledged by its role in $\mathrm{C}_{4}$ and Crassulacean Acid Metabolism (CAM) photosynthesis [1,3], though it also has key functions in $C_{3}$ plants and $C_{3}$ tissues, such as in seeds, fruits, roots, stomata, legume nodules, and others [2].

The PEPC gene family (PPC genes) includes plant-type PEPC (PTPC) and bacterialtype PEPC (BTPC) genes [4]. All PTPCs have a conserved N-terminal seryl residue that is phosphorylated by PEPC kinases (PEPCks). This residue is absent in BTPC [5]. In the model plant Arabidopsis thaliana, the PPC gene family consists of three PTPCs (PPC1-3) and one BTPC (PPC4) [6]. PPC2 transcripts are found in all organs, suggesting that it is a housekeeping gene. The PPC3 gene is expressed in roots and PPC1 is expressed in both roots and flowers, as with PPC4 [7]. The predicted PEPC proteins from a Nicotiana 
benthamiana draft genome [8] have been named on the basis of their homology to A. thaliana PEPCs (see the results section for more information).

PEPC is subjected to different post-translational modifications (PTMs), such as phosphorylation, monoubiquitination, NO-related PTMs (S-nitrosylation, Tyr-nitration), and oxidative stress-associated PTMs (carbonylation) [9-13]. In addition, the acetylation of Arabidopsis PEPCs has recently been reported [14]. These PTMs regulate PEPC activity and the turnover of the protein [13], although the biological functions of some of them are not yet fully understood.

Protein phosphorylation is the most studied PTM of PEPC. This enzyme is phosphorylated at a conserved N-terminal serine residue by PEPC kinase (PEPCk). This PTM results in a positive effect for the functional and regulatory properties of PEPC, decreasing its sensitivity to feedback inhibition by L-malate and increasing its affinity for the allosteric activator glucose-6-phosphate and $V_{\max }$ [9]. The phosphorylation of photosynthetic isoenzymes occurs during the light period in $\mathrm{C}_{4}$ plants [15] and the dark period in CAM plants [3]. The relevance of this PTM is shown in a PEPCk-deficient Kalanchoë fedtschenkoi iRNA line that shows perturbations for the CAM photosynthesis, carbohydrate metabolism, and circadian rhythms [16].

Ubiquitination is a fundamental biochemical process which controls numerous aspects of protein functions such as degradation, protein-protein interaction, and subcellular localization [17]. In different plants and tissues, two immunoreactive PEPC bands are usually detected, and the upper is thought to be a monoubiquitinated form of the lower. In fact, treatment with deubiquitinating enzyme 2 (USP2 core) causes the disappearance of the upper band. The monoubiquitination of PEPC occurs at a conserved lysine residue in castor oil seeds [18], Hakea prostata seeds [19], and sorghum seeds [10,11]. In germinating castor oil seeds, the monoubiquitination of PEPC changes the kinetic properties of the enzyme, interfering with its ability to bind PEP and enhancing sensitivity for the majority of its metabolite effectors [18]. In most of the physiological contexts that have been investigated, phosphorylation and monoubiquitination have modulated PEPC activity in opposite ways [18-20], and these two PTMs seem to be mutually restrictive. Nevertheless, the sorghum seed PEPC can be phosphorylated and monoubiquitinated at the same time $[10,11]$. This suggests that monoubiquitination could play other unknown physiological roles. In addition, ammonium stress increases the monoubiquitination of the sorghum root PEPC [12], and the meaning of this finding is still undetermined.

Autophagy is a highly conserved process used for the bulk and selective cleavage of cellular components. The element that is going to be cleaved is encapsulated in doublemembrane vesicles, termed autophagosomes, and later degraded inside the plant vacuole [21]. The process is regulated and executed by a conserved set of proteins called autophagy-related (ATG) proteins [22]. Autophagy displays a central role maintaining cellular homeostasis by removing damaged elements and thus preventing the effects of their accumulation. In addition, autophagy ensures a good management of resources by recycling the components of the cleaved elements. This is especially important under stress; in this situation, autophagy allows the preservation of key metabolic elements, meanwhile non-essential or altered elements are processed and the constituents of the latter are used for maintaining the former $[23,24]$.

Autophagy plays an important role in the remobilization of nutrients, especially in suboptimal nutrient conditions [25]. The yield and quality of grain largely depends on the mobilization of $\mathrm{N}$ from the senescent leaves to the seeds [26] and autophagy is integral to this process. An increasing body of experimental data shows that impairing autophagy has a great negative impact on nitrogen use efficiency and crop yield [27]. In Arabidopsis atg mutants, nitrogen use efficiency (NUE) is significantly decreased [28]. Similarly, maize autophagy mutants cannot efficiently remobilize $\mathrm{N}$ from old leaves to seeds [29]. On the contrary, the overexpression of $A T G$ genes enhances the level of autophagy and increases NUE, both in Arabidopsis [30] and rice [31]. 
While bulk autophagy randomly sequesters cytosolic content, selective autophagy constitutes a specific and highly controlled degradation pathway [32]. Selective autophagy requires cargo receptors which mediate selective cargo recruitment in response to diverse intra- and extra-cellular signals. Cargo receptor molecules link the cargo to the phagophore membrane via their simultaneous interaction with the cargo and ATG8 proteins on the membrane.

In contrast to the single ATG8 gene present in the genome of yeast, ATG8 generally exists as a multiprotein family in eukaryotes. Arabidopsis has nine ATG8 isoforms, annotated as ATG8a to ATG8i [33], meanwhile six isoforms have been reported in rice [34]. ATG8 provides a docking site for cargo receptors that contain short peptide motifs called ATG8-interacting motifs/LC3-interacting regions (AIMs/LIRs) [35]. Cargo receptors bind simultaneously to cargo and lipidated ATG8 or ATG8 family members. AIMs are consensus $\mathrm{F} / \mathrm{W} / \mathrm{Y}-\mathrm{X}-\mathrm{X}-\mathrm{L} / \mathrm{I} / \mathrm{V}$ sequences that can be predicted and identified by bioinformatics approaches [36,37]. Recently, a new binding motif (UIM, ubiquitin interacting motif) has been discovered on ATG8 that binds receptors containing the UIM [38].

The protein NBR1 (neighbor of the BRCA1 gene) is a cargo receptor that contributes to the autophagic clearance of ubiquitinated substrates. Plant NBR1 binds ubiquitin through a C-terminal ubiquitin-associated (UBA) domain and interacts with homologs of ATG8 via an evolutionary conserved AIM motif [39]. Arabidopsis NBR1 interacts with six of the nine Arabidopsis ATG8 proteins, and it is degraded in the vacuole in an autophagy-dependent manner. A similar protein (Joka2) has been identified in tobacco [40].

This work investigates the degradation of PEPC via autophagy and the role of NBR1 and the monoubiquitination of PEPC on its recruitment for selective autophagy. Different experimental approximations are used, including genetic and pharmacological inhibitions of autophagy, as well as pull-down experiments. The results show that a fraction of PEPC is cleaved by selective autophagy, and that monoubiquitination contributes to direct a fraction of $C_{3}$ PEPC in this pathway.

\section{Results}

\subsection{Increased Monoubiquitinated PEPC in Arabidopsis Mutants and Defective Autophagy}

Several experimental results obtained by other researchers have suggested a relationship between the monoubiquitination of PEPC and autophagy. First, in Arabidopsis plants expressing trehalose-6-P-synthase, higher levels of trehalose-6-P are accompanied by decreased amounts of monoubiquitinated PEPC [20]. Trehalose is the product of the dephosphorylation of trehalose-6-P. Trehalose has been shown to trigger autophagy in human and animal models $[41,42]$ and exists in the desiccation-tolerant grass Tripogon loliiformis [43].

Monoubiquitinated PEPC (p110) shows lower mobility in acrylamide gels than nonmonoubiquitinated PEPC (p107). This allows the identification of monoubiquitinated PEPC in gels and immunoblots as the upper band of immunoreactive PEPC protein. When trehalose was supplied to Arabidopsis plants, this decreased the monoubiquitination of PEPC in the leaves and roots (Figure 1). Although trehalose has not been demonstrated to trigger autophagy in Arabidopsis, this result prompted us to investigate the link between autophagy and monoubiquitination of PEPC.

The processing of PEPC via autophagy was explored in Arabidopsis SALK lines knockout for autophagy-related genes (ATG). The atg18a line was defective in ATG18a, which is a phosphatidylinositol 3-phosphate (PI3P) effector that interacts with ATG2 and is required for the formation of autophagosomes during nutrient stress and senescence [44]. Likewise, ATG2 and ATG5 are parts of the core machinery of autophagy [22]. NBR1, on the contrary, functions in the recruitment of selected proteins towards the specific autophagy pathway [45].

The amounts of PEPC proteins were measured in the leaves of atg2 and atg5 Arabidopsis SALK lines (Figure 2). These lines had more immunoreactive PEPC protein than the wild-type line (Col-0). As the increase was also more noticeable when the gels were 
charged by units of enzymatic activity (Figure 2a) than by $\mu$ g of protein (Figure 2b), the results suggest that inactive PEPC is accumulated as a consequence of impaired autophagy.

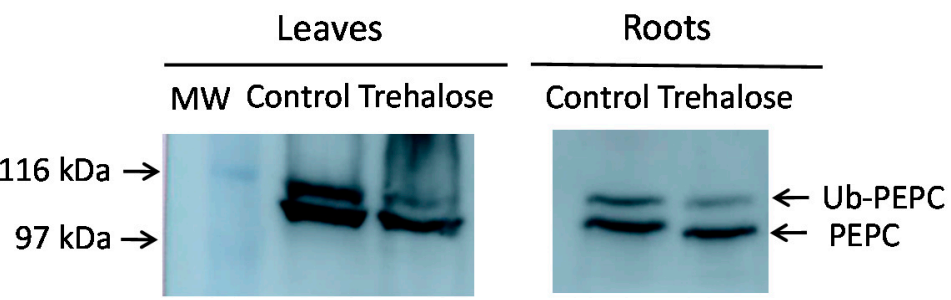

Figure 1. Trehalose decreases the monoubiquitination of Arabidopsis phosphoenolpyruvate carboxylase (PEPC). Arabidopsis plants were hydroponically grown and, when indicated, 1\% (29 mM) trehalose was supplied to the culture medium for $48 \mathrm{~h}$. The leaves and roots from six-week-old plants were pooled (30 plants). Protein aliquots corresponding to $10 \mathrm{mU}$ of PEPC were analyzed by SDS-PAGE and immunoblotted with anti-PEPC antibodies. The arrows show monoubiquitinated (Ub-PEPC) and non-monoubiquitinated PEPC. MW, molecular mass markers. The two images are of the same membrane, although several lanes are omitted for clarity.
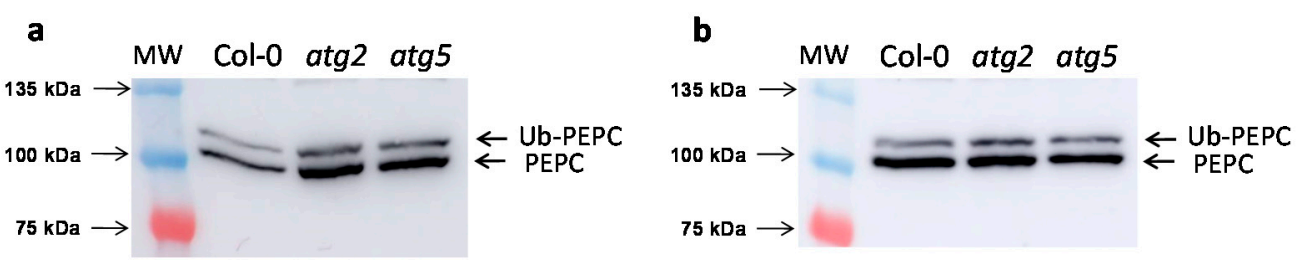

Figure 2. Arabidopsis atg2 and atg5 autophagy-defective SALK lines accumulate PEPC. Leaves from six-week-old Arabidopsis Col-0, atg2, and atg5 SALK lines were pooled (30 plants for sample). Protein aliquots from crude extracts were analyzed by SDS-PAGE and immunoblotted with antiPEPC antibodies. (a) Results for $5 \mathrm{mU}$ of PEPC from leaf extracts. (b) Results for $50 \mu \mathrm{g}$ of proteins from leaf extracts.

Similar results were obtained with the leaves and roots of $n b r 1$ (Figure $3 a$ ) and atg18a lines (Figure $3 b$ ). In $n b r 1$ leaves, the accumulation of monoubiquitinated PEPC was especially evident (Figure 3a, left), represented by the upper band, which was revealed by anti-ubiquitin antibodies (Figure 3a, right). Increased p110/p107 ratios were detected to different extents in all the defective autophagy lines (Table 1 ).

Table 1. The amounts of monoubiquitinated PEPC increased in autophagy-defective Arabidopsis lines.

\begin{tabular}{ccc}
\hline & \multicolumn{2}{c}{ Ratio of $\mathbf{p 1 1 0 / \mathbf { p } 1 0 7}$} \\
\cline { 2 - 3 } & Leaves & Roots \\
\hline Col-0 & $0.34 \pm 0.04$ & $0.11 \pm 0.02$ \\
atg2 & $0.53 \pm 0.04$ & $0.18 \pm 0.02$ \\
atg5 & $0.48 \pm 0.03$ & $0.16 \pm 0.02$ \\
nbr1 & $0.58 \pm 0.16$ & $0.38 \pm 0.19$ \\
$\operatorname{atg} 18 a$ & $0.50 \pm 0.07$ & $0.19 \pm 0.03$ \\
\hline
\end{tabular}

Leaves or roots from six-week-old Arabidopsis Col-0, atg2, atg5, nbr1, and atg18a SALK lines were pooled (30 plants for sample). Proteins aliquots from crude extracts from leaf or roots were analyzed by SDS-PAGE and immunoblotted with anti-PEPC antibodies. The ratios (Ub-PEPC/PEPC) of the signals were calculated. The table shows quantitative data (mean $\pm \mathrm{SE}, n=5$ ) for the ubiquitination.

The accumulation of monoubiquitinated PEPC was observed mainly in standard conditions. In plants subjected to stress, the upper band (Ub-PEPC) typically decreased, both in Col-0 and autophagy-deficient SALK lines. As an example, this could be seen for Col-0 and for atg18a under $\mathrm{N}$ starvation (Figure 3b). The results in atg18a, whose bulk 
autophagy was expected to be severely compromised, indicated that Ub-PEPC could be also processed by autophagy-independent mechanisms.

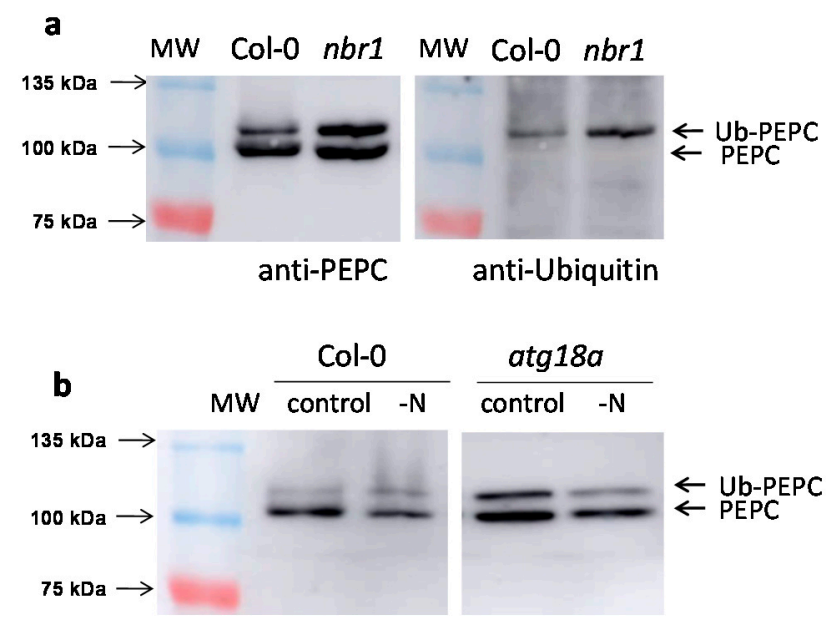

Figure 3. The amount of monoubiquitinated PEPC increases in the $n b r 1$ and atg18a SALK lines. Arabidopsis Col-0, nbr1, and atg18a SALK lines were hydroponically grown for six weeks. Leaves from 30 plants were pooled and protein aliquots corresponding to $10 \mathrm{mU}$ of PEPC were analyzed by SDS-PAGE. (a) Leaf extracts from Col-0 and nbr1. Immunoblots with anti-PEPC and anti-ubiquitin antibodies of the same membrane. (b) Leaf extracts from Col- 0 and $\operatorname{atg} 18 a$. When indicated, $\mathrm{N}$ was suppressed from the culture medium for 1 week. Several lanes are omitted for clarity.

Taken together, the results for Arabidopsis indicate that at least a fraction of $\mathrm{C}_{3}$-type PEPC was degraded via selective autophagy. The monoubiquitination of the protein could be marking a fraction of the PEPC protein towards this pathway. Nevertheless, autophagy is not the only main pathway by which PEPC is degraded.

\subsection{Chemical Inhibition of Autophagy in Cultured N. benthamiana Cells Increased the Amount of Monoubiquitinated PEPC}

The results obtained via the genetic inhibition of autophagy (Arabidopsis mutants) were further studied in terms of the chemical inhibition of the degradation of autophagic substrates. The following experiments were performed with cultured $N$. benthamiana cells. Tobacco cells were cultured in the dark and organic $C$ was supplied in the form of sucrose. When sucrose was absent, PEPC activity decreased and was nearly undetectable by $10 \mathrm{~d}$. After $5 \mathrm{~d}$ without sucrose, PEPC represented about $30 \%$ of the activity with sucrose and it was fully recovered by the addition of sucrose, showing that the decreased PEPC activity was not due to death of the cells (Figure 4a).

If sucrose starvation triggers the autophagic degradation of PEPC, the addition of inhibitors in this process should preserve the protein. Three different inhibitors were used to test this hypothesis. First, 3-methyladenine (3-MA) was used, which impedes the formation of autophagosomes by inhibiting phosphatidylinositol-3-kinase (PI3K) [46]. Concanamycin A (ConcA) inhibits vacuolar-type ATPase, preventing vacuolar acidification and blocking the degradation of autophagic bodies inside vacuoles [47]. E64 inhibits Cys-proteases and stabilizes autophagic bodies inside vacuoles [48]. The presence of either of the inhibitors increased the amount of immunoreactive PEPC protein in sucrose-starved cells (Figure $4 \mathrm{~b}$ ). Interestingly, 3-MA noticeably increased the amount of mono-ubiquitinated PEPC, both in the absence or in the presence of sucrose (Figure $4 b, c)$. These results indicate that PEPC is processed via autophagy, both in control conditions and under sucrose starvation, and that monoubiquitination could be a mark for recruitment to selective autophagy. The differences between 3-MA and the other two inhibitors suggest that ubiquitin is removed from PEPC inside the autophagosome before its inclusion in the vacuole. It has been reported that ubiquitin and other ubiquitin-like modifiers are recycled along degradation 
processes [49]. In the same line, the ubiquitin-like modifier PE-ATG8 is deconjugated by ATG4 and then recycled [50].
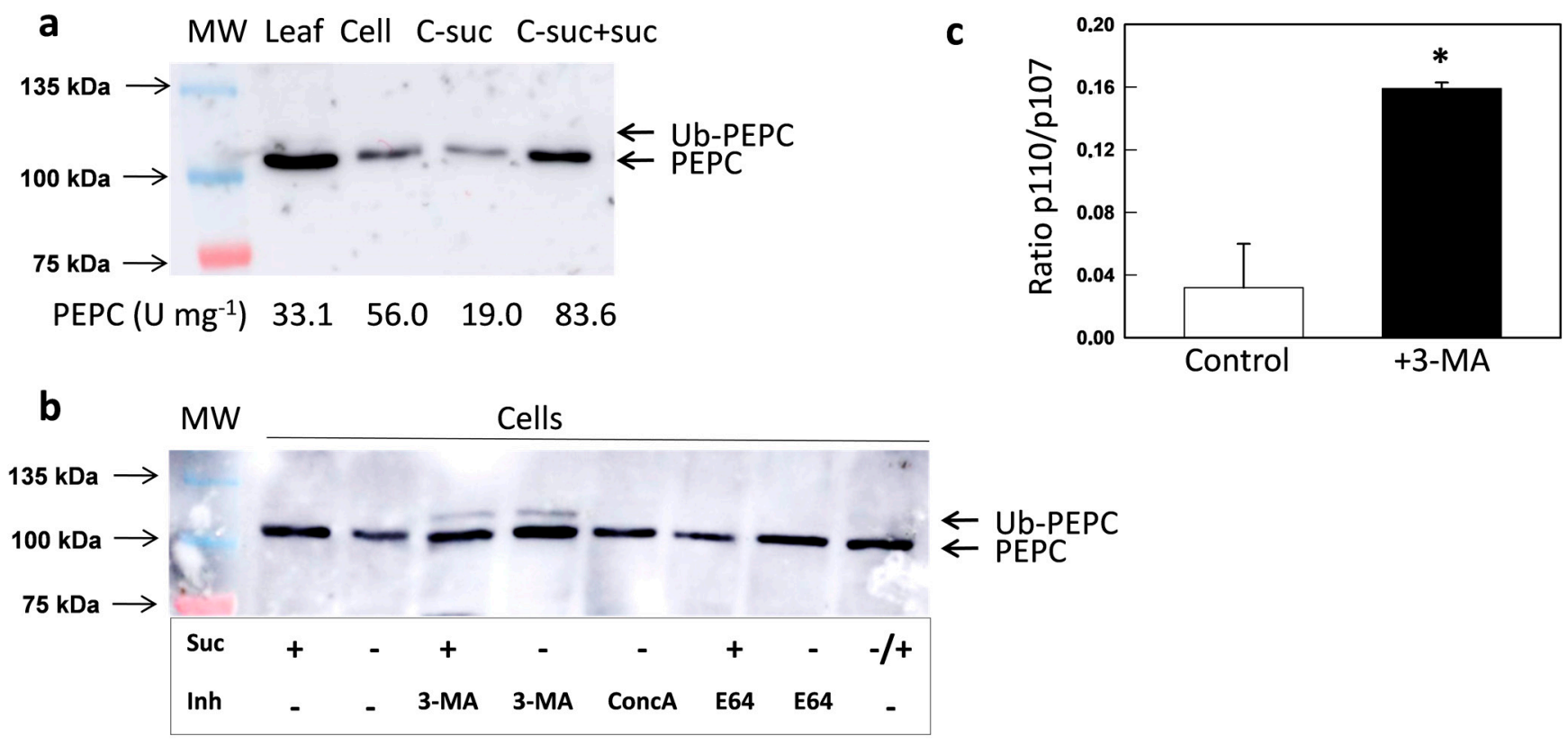

Figure 4. Effect of sucrose starvation and inhibitors on the PEPC of $N$. benthamiana culture cells. Crude extracts were prepared with leaves or cultured cells. Protein aliquots corresponding to $30 \mu \mathrm{g}$ were analyzed by SDS-PAGE and immunoblotted with anti-PEPC antibodies. (a) When indicated, sucrose was suppressed from the culture medium of cells for $5 \mathrm{~d}$ (C-suc) or suppressed for $5 \mathrm{~d}$ and then resupplied for $2 \mathrm{~d}$ (C-suc+suc). The numbers under the immunoblots show the PEPC activities of extracts. (b) Cells were cultured with a control medium for 5 days. When indicated, sucrose was suppressed ( $5 \mathrm{~d}$ ) or suppressed for $5 \mathrm{~d}$ and then resupplied for $2 \mathrm{~d}(-/+)$. 3-MA was added at $2.5 \mathrm{mM}(5 \mathrm{~d})$, along with ConcA at $1 \mu \mathrm{M}(16 \mathrm{~h})$ and E64 at $10 \mu \mathrm{M}(16 \mathrm{~h})$. (c) The ratio of p110/p107 (Ub-PEPC/PEPC) of the signal with or without 3-MA was calculated. * $p<0.05$ versus Col-0 ( $t$-test, $n=3)$.

Phylogenetic and sequence analysis of predicted N. benthamiana PEPCs was performed with data from the new draft sequence of the $N$. benthamiana genome [8]. Six complete PEPC sequences were found in the database. In order to evaluate the homology and their phylogenetic relationships, the entire predicted amino acid sequences of the six PEPCs were compared with the protein sequences of PEPCs from A. thaliana. From this alignment, a phylogenetic tree and a phylogenetic distance matrix were constructed (Figure 5).

The BTPCs (AtPPC4 and NbPPC4) constituted a group separated from PTPCs (Figure 5a). The PTPC proteins were named on the basis of their homology and phylogenetic distance as compared to the $A$. thaliana PEPCs. The five putative protein-encoded PTPCs in N. benthamiana had a high level of homology between them as the amino acid sequences were highly conserved. One of the proteins presented more homology to AtPPC2 and comprised an independent cluster with AtPPC2 (Figure 5a). Relationships among the other four PTPCs were unresolved and, if so, they were weakly supported in both the BI and ML analyses. Three of them (NbPPC3.1-3) are very similar and showed more homology and less evolutionary distances with respect to AtPPC3, while one (NbPPC1) was more similar to AtPPC1 (Figure 5b).

The identities of the two bands were revealed by the anti-PEPC antibodies that exist in extracts of cultured tobacco cells and were confirmed by MALDI-TOF MS/MS. Peptide mass fingerprinting revealed that both the upper (p110) (Figure S1) and the lower (p100) fingerprints matched with PPC3 (Figure S2). Although the score for the p100 band was under the desired value, the identification was supported by the likeness of the MALDI fingerprints for the two bands (Figure S3). 


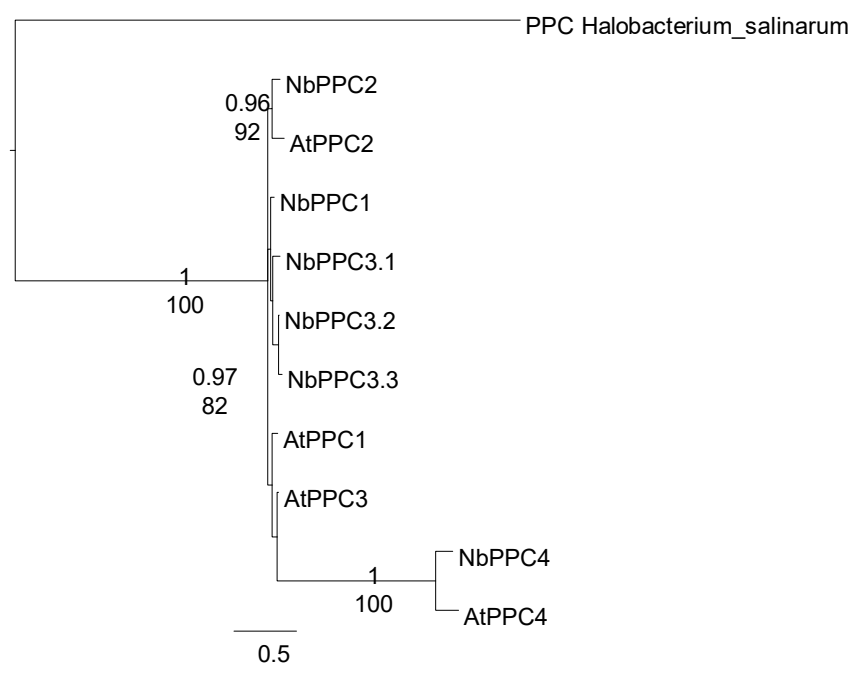

b

$\begin{array}{lcccccccccc}\text { Outgroup } & \begin{array}{c}\text { Out } \\ * * *\end{array} & \text { NbPPC1 } & \text { NbPPC3.2 } & \text { NbPPC2 } & \text { NbPPC3.3 } & \text { NbPPC4 NbPPC3.1 AtPPC4 } & \text { AtPPC3 } & \text { AtPPC2 } \\ \text { NbPPC1 } & 0.774 & * * * * & & & & & & & & \\ \text { NbPPC3.2 } & 0.778 & 0.072 & * * * * & & & & & & & \\ \text { NbPPC2 } & 0.781 & 0.114 & 0.133 & * * * * & & & & & & \\ \text { NbPPC3.3 } & 0.778 & 0.094 & 0.028 & 0.151 & * * * * & & & & & \\ \text { NbPPC4 } & 0.815 & 0.548 & 0.545 & 0.544 & 0.559 & * * * * & & & & \\ \text { NbPPC3.1 } & 0.778 & 0.083 & 0.094 & 0.132 & 0.107 & 0.555 & * * * * & & & \\ \text { AtPPC4 } & 0.817 & 0.556 & 0.551 & 0.549 & 0.565 & 0.232 & 0.558 & * * * * & & \\ \text { AtPPC3 } & 0.783 & 0.110 & 0.121 & 0.132 & 0.142 & 0.540 & 0.112 & 0.551 & * * * * & \\ \text { AtPPC2 } & 0.789 & 0.134 & 0.144 & 0.130 & 0.159 & 0.548 & 0.150 & 0.559 & 0.152 & * * * * \\ \text { AtPPC1 } & 0.778 & 0.105 & 0.126 & 0.123 & 0.146 & 0.549 & 0.126 & 0.557 & 0.082 & 0.146\end{array}$

Figure 5. Phylogenetic analysis of N. benthamiana PEPCs. (a) Phylogeny of phosphoenolpyruvate carboxylase (PPC) proteins and their isoforms in N. benthamiana and A. thaliana. For protein identifi-

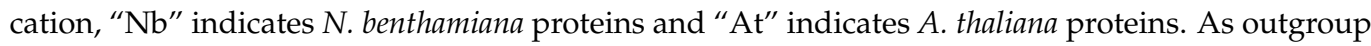
was used a PEPC from Halobacterium salinarum (HsPPC). Bootstrap analysis was carried out with 100 replicates. Number at the branches correspond to the bootstrap frequencies for each branch. (b) Evolutionary divergence matrix estimated from PEPCs proteins sequences. The rate variation among sites was modeled with a gamma distribution (shape parameter $=1$ ). ${ }^{* * * *}$ means "not applicable".

The next step was to confirm that the p110 band corresponded to the monoubiquitination of p100. PEPC present in crude extracts from different sources was immunoprecipitated by incubation with anti-PEPC antibodies [51]. Anti-ubiquitin antibodies exclusively revealed the p110 band in the precipitate from $N$. benthamiana leaves and roots, as well as $A$. thaliana leaves (Figure 6a). Similar results were obtained with $N$. benthamiana cells (Figure 6b) when 3-MA was added to the growing medium (lane 3). In the absence of 3-MA, the amount of monoubiquitinated PEPC was barely noticeable (lane 2). This result demonstrates that the upper band effectively corresponds to an ubiquitinated form of PEPC, and that the amount of monoubiquitinated PEPC was increased when the formation of autophagosomes was blocked. 


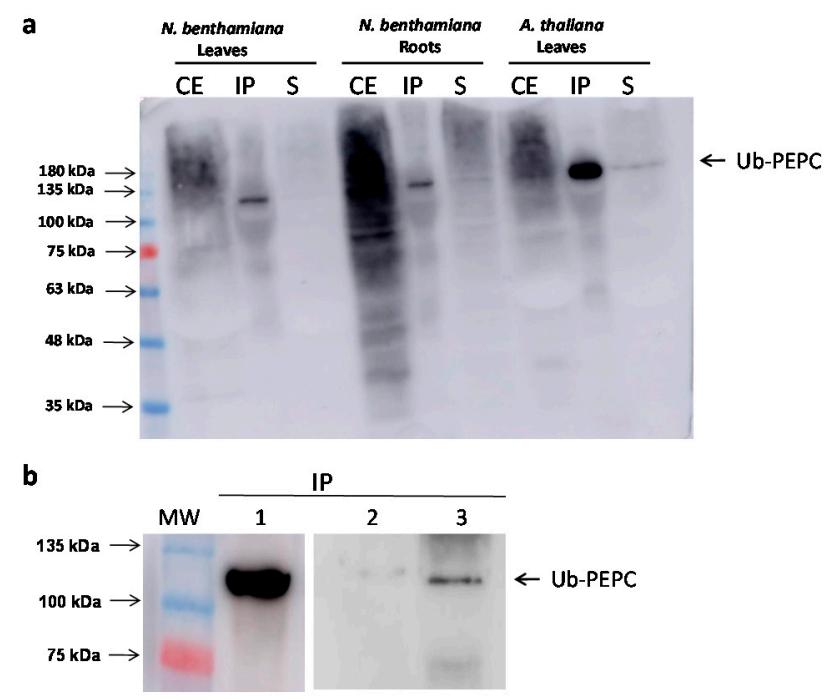

Figure 6. Monoubiquitinated PEPC is revealed by anti-Ubiquitin antibodies in immunoprecipitates. Crude extracts (CE) were obtained from different plant tissues $(0.5 \mathrm{~g} / \mathrm{mL}$ extraction buffer for leaves, and $1 \mathrm{~g} / \mathrm{mL}$ extraction buffer for roots and cells) and PEPC contained in $3 \mathrm{~mL}$ of crude extracts was immunoprecipitated with anti-PEPC antibodies. Finally, immunoprecipitates were analyzed by immunoblotting and detected with anti-Ubiquitin antibodies. (a) PEPC immunoprecipitation from Nicothiana benthamiana leaves and roots and A. thaliana leaves. CE, $30 \mu \mathrm{g}$ protein from crude extract; IP, immunoprecipitate; S, supernatant. (b) PEPC immunoprecipitated from extracts of $A$. thaliana leaves (lane 1), N. benthamiana cells (lane 2), and 3-MA-treated N. benthamiana cells (lane 3).

\subsection{Pull-Down with GST-NBR1 and GFP-ATG8a}

Several experimental approaches were used to investigate a possible degradation of PEPC via recruitment by NBR1, which interacts with ubiquitinated proteins towards selective autophagy. First, experiments were carried out using truncated SbNBR1 containing UBA1, UBA2, and AIM, which was purified and subsequently used alongside glutathione agarose resin. This resin binds to glutathione $S$-transferase (GST) fusion proteins. Experiments were performed with Arabidopsis leaves and roots and N. benthamiana cultured cells.

Pull-down experiments were performed with leaves (Figure 7a) and roots (Figure 7b) of Arabidopsis lines Col-0, atg2-2, and atg5-1. Anti-PEPC antibodies revealed a $65 \mathrm{kDa}$ peptide that interacted with GST-NBR1 in leaves and roots extracts from all the lines. In addition, a $100 \mathrm{kDa}$ anti-PEPC immunoreactive peptide was observed in the leaves of the atg5-1 line. The amounts of co-immunoprecipitated PEPCs were slightly higher in the autophagy-deficient lines.

The pull-down experiments with truncated GST-NBR1 in N. benthamiana cells extracts obtained different results in different conditions. Experiments were conducted with the control, without sucrose and/or in presence of the inhibitors 3-MA, E64, and ConcA (Figure 8). Anti-PEPC antibodies revealed a $65 \mathrm{kDa}$ peptide in the pull-down in all the experiments. In addition, in the presence of 3-MA, an intact $100 \mathrm{kDa}$ peptide was also detected.

Finally, the interaction between ATG8 and PEPC was evaluated using immunoprecipitation following transient expression in N. benthamiana (Figure 9). Leaves of N. benthamiana were infiltrated with recombinant GFP-ATG8CL. Immunoprecipitation was performed by affinity chromatography with GFP-Trap ${ }^{\circledR}$ A beads (Chromotek), and elution of the proteins from the beads was performed by heating for $5 \mathrm{~min}$ at $95^{\circ} \mathrm{C}$. The typical double band, corresponding to monoubiquitinated and no-ubiquitinated PEPC, was revealed by anti-PEPC antibodies in leaf extracts. A 63-kDa anti-PEPC immunoreactive peptide was recovered in the pull-down. Peptide mass fingerprinting and MALDI-MS/MS showed that the peptide was identified as Niben101Scf03628g14021 (NbPPC2) (Figure S4). The higher score was 
with Niben101Scf03487g00014, which is a fragmented PEPC lacking a N-terminal end. This result suggests an interaction between ATG8 and PEPC, either directly or indirectly via endogenous NBR1.

a

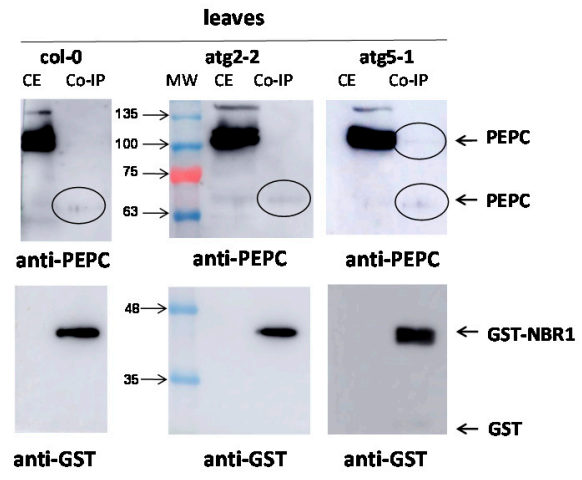

b

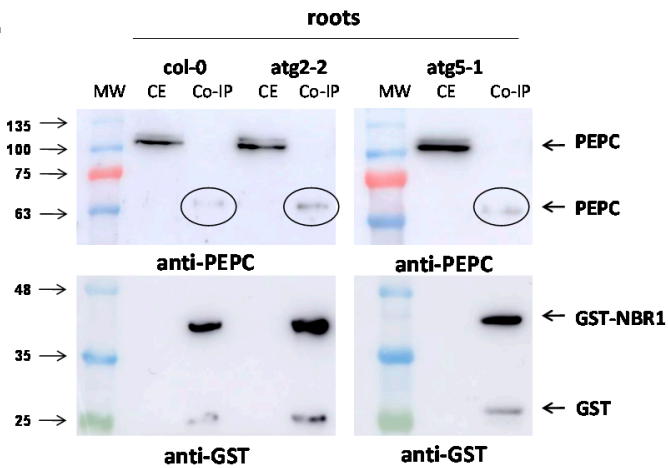

Figure 7. Co-immunoprecipitation of PEPC with GST-NBR1 in Arabidopsis lines. Crude extracts from leaf (a) and root (b) tissues of Col-0, atg2, and atg5 Arabidopsis (six weeks) were incubated overnight at $4{ }^{\circ} \mathrm{C}$ with purified GST-NBR1 pre-bound to Gluthatione Sepharose ${ }^{\circledR} 4 \mathrm{~B}$ (GE Healthcare). Then, extracts were centrifuged at $1000 \times g$ for $2 \mathrm{~min}$ at $4{ }^{\circ} \mathrm{C}$, washed five times, and co-precipitated proteins were eluted by heating at $95^{\circ} \mathrm{C}$ for $5 \mathrm{~min}$ with a dissociation buffer. Afterwards, $50 \mu \mathrm{g}$ of proteins from crude extracts (CE) and corresponding amounts of co-precipitated proteins (Co-IP) were analyzed by SDS-PAGE and immunoblotted with anti-PEPC and anti-GST antibodies.

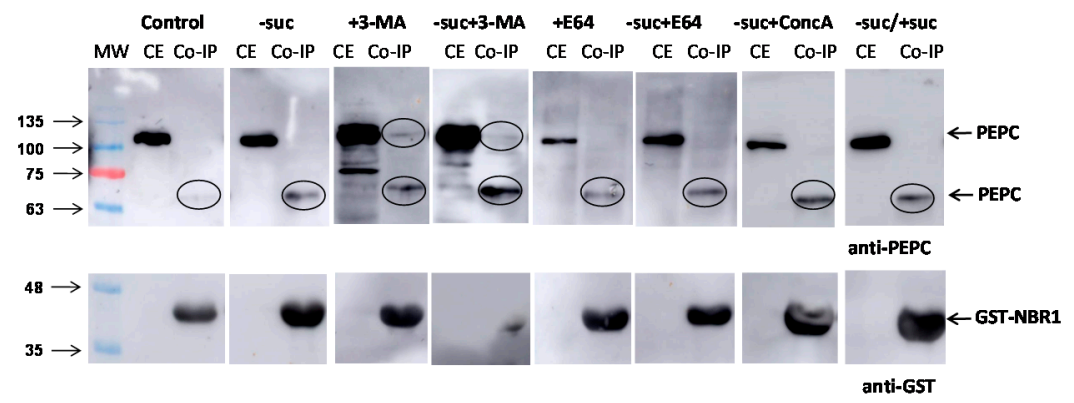

Figure 8. Co-immunoprecipitation of PEPC with GST-NBR1 in N. benthamiana cells. Crude extracts were prepared from five-day-old $N$. benthamiana cell cultures and aliquots containing $50 \mu$ g of protein were used in the pull-down experiments. When indicated, cells were kept without sucrose (-suc), or

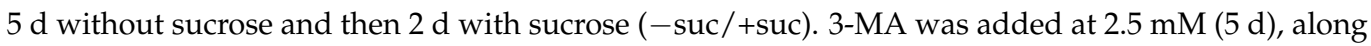
with ConcA at $1 \mu \mathrm{M}(16 \mathrm{~h})$, and $\mathrm{E} 64$ at $10 \mu \mathrm{M}(16 \mathrm{~h})$. The other conditions are the same as in Figure 6 . $\mathrm{CE}$, crude extracts; Co-IP, co-precipitated proteins. 


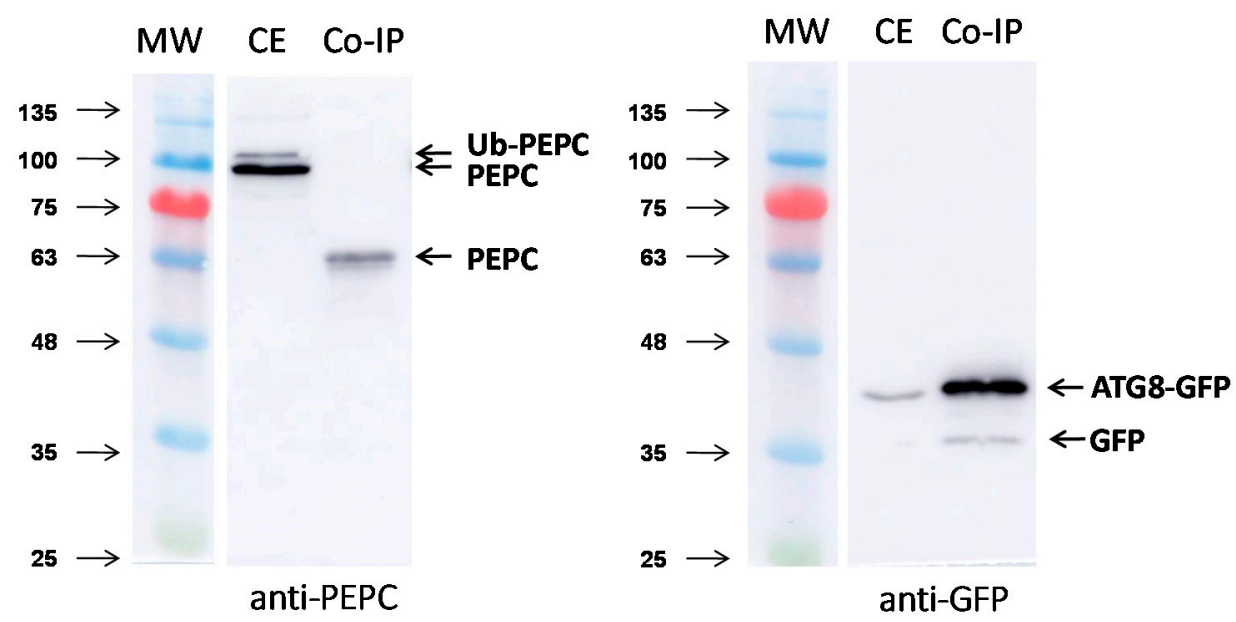

Figure 9. Co-immunoprecipitation of PEPC with GFP-ATG8CL in N. benthamiana. A transformed Agrobacterium tumefaciens strain GV3101 line carrying potato ATG8CL fused to green fluorescent protein (GFP) has infiltrated N. benthamiana. At $60 \mathrm{~h}$ after agroinfiltration, proteins were extracted from infiltrated leaves using a $2 \mathrm{~mL}$ GTEN buffer per $\mathrm{g}$ of tissue. Crude extracts were incubated with GFP-Trap ${ }^{\circledR} \_$A (Chromotek) for $2 \mathrm{~h}$ at $4^{\circ} \mathrm{C}$. Then, extracts were centrifuged at $1000 \mathrm{~g}$ for 2 min at $4{ }^{\circ} \mathrm{C}$, washed five times, and co-precipitated proteins were eluted by heating at $95{ }^{\circ} \mathrm{C}$ for 5 min with a dissociation buffer. Afterwards, $15 \mu \mathrm{L}$ of the crude extracts (CE) and co-precipitated proteins (Co-IP) were immunoblotted with the anti-PEPC (left) and anti-GFP (right) antibodies.

By using two different bioinformatics tools (iLIR and hfAIM), we found several putative AIM domains in all PEPCs from Arabidopsis and N. benthamiana [36,37]; however, with only AtPPC2 and AtPPC4, both methods identified the same motif in the protein (Table S1). To add another criterion of significance to the results, we used the positionspecific scoring matrix (PSSM) index calculated with the iLIR method. This index improves the accuracy of the results with a threshold of 13 for the results to be taken into account as possible AIM domains [37]. Interestingly, only the BTPC isoform in Arabidopsis AtPPC4 followed this criterion, with a PSSM value of 23, suggesting that only this PEPC protein is bound by ATG8; however, the AtPPC4 protein was almost absent in all tissues analyzed in this work [52] and more suitable tissues (i.e., pollen) should be used to certify ATG8 binding. In light of these results, we can conclude that, although it is possible, PTPCs from Arabidopsis and N. benthamiana are unlikely to bind ATG8 directly by AIM domains.

\section{Discussion}

Among the most stress-resistant plants, there are many $\mathrm{C}_{4}$ and CAM species, particularly for drought and salt stress [53]. In addition, $C_{3}$-type PEPCs have extensively documented roles in response to environmental stresses, such as $\mathrm{Al}$ and $\mathrm{Cd}$ toxicity $[54,55]$, $\mathrm{P}$ starvation [52], and ammonium stress [12]. Work at our laboratory has shown notable results with Sorghum bicolor, which has both $\mathrm{C}_{4}$ and $\mathrm{C}_{3}$ type PEPCs, where the salt and ammonium stresses have increased the amount of PEPC proteins in roots while enhancing the degree of phosphorylation in leaves $[12,56]$. The mechanisms responsible for these effects are complex, and they include both changes of $P P C$ and PPCK gene expression and increased stability of PEPC and PEPCk proteins. The mechanisms controlling the degradation of PEPC and the role of PTMs on the stability of the protein are not yet fully understood. This paper has investigated the autophagic degradation of PEPC and the role of monoubiquitination in regulating the stability of PEC proteins in terms of marking towards selective autophagy.

Although there is experimental evidence that shows that both photosynthetic PEPCs and PEPCks can be polyubiquitinated and degraded $\mathrm{kDa}$ by the $26 \mathrm{~S}$ proteasome $[57,58]$, the monoubiquitination of photosynthetic PEPCs has not been reported. This work has focused 
on $\mathrm{C}_{3}$-type PEPCs, investigating whether monoubiquitination has a role in recruiting proteins towards selective autophagy.

Mutations in core ATG genes in Arabidopsis cause defective autophagy and hypersensitivity to various types of nutrient, and also to abiotic and biotic stress factors [59]. These mutants accumulate proteins that are otherwise degraded by autophagy. An increase of the amount of PEPC, and, specifically monoubiquitinated PEPC, was found in the atg2, atg5, and atg18a Arabidopsis lines, which are defective in terms of core ATG proteins. Remarkably, monoubiquitinated PEPC accumulated in the $n b r 1$ line, which is specifically deficient in selective autophagy. These results suggest that specific autophagy is involved in basal maintenance of PEPC. This is supported by the results of Dr Vierstra's group. In a maize mutant lacking the core autophagy protein ATG12 (atg12-1) [60], $\mathrm{C}_{3}$-type PEPC accumulated in old but not in young leaves (Fionn McLoughlin personal communication). Similar results were obtained with the chemical inhibition of autophagic degradation of cargo in cultured tobacco cells. Finally, pull-down experiments demonstrated the interaction between NBR1 and PEPC in Arabidopsis leaves and roots and cultured tobacco cells, as well as between ATG8 and PEPC in N. benthamiana leaves.

Monoubiquitinated PEPC was not recovered in the pull-down experiments, as it should have been expected. In addition, intact $100 \mathrm{kDa}$ peptides were rarely found. In most cases, fragmented PEPC peptides were revealed by anti-PEPC antibodies after pulldown. It is possible that monoubiquitinated PEPC is cleaved before its recruitment to the autophagosome. Alternatively, it is also feasible that PEPC is cleaved (for example, by cathepsin proteases) and then monoubiquitinated. Experimental data do not allow distinguishing between these two alternatives. It could be hypothesized that PEPC proteins directed towards selective autophagy are altered forms with a higher sensitivity to proteolytic cleavage. We have recently shown that the interaction of sorghum PEPC with anionic phospholipids changes its conformation and this increases its sensibility to cysteine proteases [61].

Autophagy allows the degradation of damaged elements and the recycling of their components, ensuring good management of resources and preventing the effects of the buildup of dysfunctional elements. This work shows that a fraction of $C_{3}$-type PEPC is cleaved via selective autophagy. In addition, a new function has been attributed to the monoubiquitination of PEPC, marking the protein towards selective autophagy, increasing the knowledge about the mechanisms that control the stability and turnover of the PEPC protein.

\section{Materials and Methods}

\subsection{Plant Material and Growth Conditions}

All A. thaliana plants used in this study were from the Columbia (Col-0) background. Seeds of SALK lines atg18a and $n b r 1$ were obtained from the Nottingham Arabidopsis Stock Centre (NASC, London, UK; http:/ / arabidopsis.info). Mutant lines were analyzed, and homozygosity was confirmed by PCR analysis. The atg2 and atg 5 lines were kindly provided by Dr. Yasin Dagdas (Gregor Mendel Institute of Molecular Plant Biology, Vienna, Austria). Arabidopsis seed surfaces were sterilized with $70 \%$ ethanol for $10 \mathrm{~min}$ and a $50 \% \mathrm{HClO}$ solution for $10 \mathrm{~min}$. Finally, the seeds were rinsed 8 to 10 times with sterile water. Seeds were then stratified for $3 \mathrm{~d}$ at $4{ }^{\circ} \mathrm{C}$ in the dark in a $0.1 \%$ agar solution in water to synchronize germination. Seeds were placed in an Araponics ${ }^{\circledR}$ systems on a $0.65 \%$ agar and were supplied with half strength Murashige and Skoog (MS) media. Plants were grown with a short day regime, with $8 \mathrm{~h}$ in the light $\left(22{ }^{\circ} \mathrm{C}, 60 \%\right.$ relative humidity) and $16 \mathrm{~h}$ of dark $\left(18^{\circ} \mathrm{C}, 70 \%\right.$ relative humidity). The light intensity was $140 \mu \mathrm{mol}$ photons $\mathrm{m}^{-2}$ $\mathrm{s}^{-1}$ PAR.

N. benthamiana seeds were sterilized by washing with $20 \%$ bleach $(20 \mathrm{~min})$ and several times with distilled water. Plants were grown on a solid substrate in a growth chamber with a day/night cycle of $12 \mathrm{~h}$ in the light $\left(25^{\circ} \mathrm{C}, 60 \%\right.$ relative humidity) and $12 \mathrm{~h}$ in the dark $\left(20^{\circ} \mathrm{C}, 70 \%\right.$ relative humidity). The light intensity was $350 \mu \mathrm{mol}$ photons $\mathrm{m}^{-2}$ 
$\mathrm{s}^{-1}$ PAR. Plants were grown for 4-5 weeks and then used in experiments for transitory expression after infiltration with Agrobacterium tumefaciens.

\subsection{N. benthamiana Cell Cultures}

Surfaced-sterilized seeds were sown on petri dishes containing germination media ( $50 \%$ MS medium, $2 \%$ sucrose, $1 \%$ agar). After three weeks, roots were excised $(0.5 \mathrm{~cm})$ and roots sections were transferred to Petri dishes containing callus induction media $\left(4.4 \mathrm{~g} \mathrm{~L}^{-1}\right.$ MS, $2 \%$ glucose, $0.8 \%$ agar, $0.5 \mathrm{mg} \mathrm{L}^{-1}$ 2,4-dichlorophenoxyacetic acid, $0.05 \mathrm{mg} \mathrm{L}^{-1}$ kinetin, $0.5 \mathrm{~g} \mathrm{~L}^{-1}$ MES, pH 5.7). Dishes were sealed with Leukopor tape and kept in continuous white light $\left(20 \mu \mathrm{mol}\right.$ photons $\mathrm{m}^{-2} \mathrm{~s}^{-1}$ PAR) for 2-3 weeks until calluses were obtained.

Pieces of friable callus $(0.3 \mathrm{~g})$ were transferred to a $100 \mathrm{~mL}$ flask containing a $20 \mathrm{~mL}$ sterile culture medium (4.4 $\mathrm{g} \mathrm{L}^{-1}$ MS supplemented with Gamborg B5 salts, $\mathrm{pH}$ 5.8, 3\% sacarose, $0.5 \mathrm{mg} \mathrm{L}^{-1} \alpha$-naphtaleneacetic acid, $0.05 \mathrm{mg} \mathrm{L}^{-1}$ kinetin). Cells were kept in an orbital shaker for 10 days under continuous light (100 $\mu \mathrm{mol}$ photons $\mathrm{m}^{-2} \mathrm{~s}^{-1}$ PAR) and then cells were transferred to $80 \mathrm{~mL}$ of a fresh culture medium. The cultures were subsequently kept in the dark and subcultured once a week by transferring $25 \%$ of the culture to a flask containing $70 \mathrm{~mL}$ of a fresh culture medium.

\subsection{Determination of Enzyme Activity and Protein Quantification}

Protein extracts were obtained by grinding $0.2 \mathrm{~g}$ fresh weight of leaf or root tissue in a $1 \mathrm{~mL}$ extraction buffer containing $0.1 \mathrm{M}$ Tris- $\mathrm{HCl}, \mathrm{pH} 7.5,20 \%(v / v)$ glycerol, $1 \mathrm{mM}$ EDTA, $10 \mathrm{mM} \mathrm{MgCl}$, a protease inhibitor cocktail (Sigma), $10 \mathrm{mM}$ potassium fluoride, and $14 \mathrm{mM} \beta$-mercaptoethanol. The homogenate was centrifuged at $15,000 \times g$ for $2 \mathrm{~min}$ and PEPC activity was quantified in the supernatant.

PEPC activity was measured spectrophotometrically at optimal $\mathrm{pH}$ of 8.0 using a NAD-MDH-coupled assay at $2.5 \mathrm{mM}$ PEP [62]. A single enzyme unit (U) is defined as the amount of PEPC that catalyzes the carboxylation of $1 \mu \mathrm{mol}$ of phosphoenolpyruvate per minute at a $\mathrm{pH}$ of 8 and temperature of $30^{\circ} \mathrm{C}$.

\subsection{Antibodies}

Polyclonal antibodies against $\mathrm{C}_{4}$-type PEPC from sorghum leaves (rabbit anti- $\mathrm{C}_{4}$ PEPC) were prepared as described in [63] and were used at a ratio of 1:3000. The rabbit anti-ubiquitin antibodies (anti-Ubiquitin) were purchased from Millipore (catalog number 05-944) and used at a ratio of 1:2000. Anti-GST monoclonal antibodies were produced by mice against a recombinant GST protein and obtained from Santa Cruz Biotechnology (product code sc-138). The rat anti-GFP monoclonal antibodies were raised against a recombinant green fluorescent protein and were obtained from Chromotek (product code 3h9-100). Secondary antibodies conjugated to horseradish peroxidase were obtained from: (i) Invitrogen (anti-rabbit, product code 31460); (ii) Novus (anti-mouse, product code NB7539); (iii) CST (anti-rat, product code 7077S). For the chemoluminescent reaction, Supersignal West Pico Chemiluminescent Substrate (Thermo Scientific) and WesternBright Quantum (Advansta) were used, and the Amersham Imagier 600 was used for imaging.

\subsection{Electrophoresis and Protein Gel Blot Analysis}

Samples containing proteins were denatured by boiling $\left(3 \mathrm{~min}, 90^{\circ} \mathrm{C}\right)$ in the presence of a dissociation buffer (100 mM Tris- $\mathrm{HCl}, \mathrm{pH} 8,25 \%$ [ $v / v]$ glycerol, $1 \%$ [ $w / v]$ SDS, $10 \%$ $[v / v] \beta$-mercaptoethanol, and $0.05 \%[w / v]$ bromophenol blue). The denatured proteins were separated by SDS-PAGE in a Miniprotean electrophoresis cell (Bio-Rad) and stained with Coomassie Brilliant Blue R-250 or electroblotted onto a nitrocellulose membrane (N-8017 from Sigma) at $10 \mathrm{~V}\left(3 \mathrm{~mA} \mathrm{~cm}{ }^{-2}\right)$ for $2 \mathrm{~h}$ in a semi-dry blot transfer apparatus (Bio-Rad). Membranes were blocked in Tris-buffered saline $(0.02 \mathrm{M}$ Tris- $\mathrm{HCl}$ and $0.15 \mathrm{M}$ $\mathrm{NaCl}, \mathrm{pH} 7.5)$ containing $5 \%(w / v)$ powdered milk, and bands were immunochemically labeled via overnight incubation of the membrane at $4{ }^{\circ} \mathrm{C}$ in $20 \mathrm{~mL}$ of Tris-buffered saline 
containing antisera. The Multi Gauge (Fujifilm) software package was used for graphical analysis and the quantification of the immunoblot images.

\subsection{Recombinant Protein Expression and Purification}

Using a Gateway ${ }^{\circledR}$ cloning system, a truncated SbNBR1 containing two ubiquitinassociated domains (UBA) and one ATG8 interacting motif (AIM) was cloned into a pGEXKG vector (kindly provided by Dr. Galván-Ampudia from the University of Amsterdam), then fused to glutathione S-transferase (GST). The Escherichia coli BL21 strain was used for expression of the GST-NBR1 protein from the previous vector, induced by $1 \mathrm{mM}$ isopropyl $\beta$-D-1-thiogalactopyranoside (IPTG) for $6 \mathrm{~h}$. The soluble fraction from the bacterial lysate was incubated with Glutathione Sepharose ${ }^{\circledR}$ 4B (GE Healthcare) to bind GST-NBR1, and the agarose was used for further pull-down experiments.

\subsection{Pull-Down Experiments}

For the pull-down experiments, GFP-Trap ${ }^{\circledR} \_$A (Chromotek) and a GST-NBR1 prebound agarose (described in Section 4.6) were incubated with protein crude extracts for $2 \mathrm{~h}$ (GFP-Trap) or overnight (GST-NBR1) at $4{ }^{\circ} \mathrm{C}$ in the presence of a GTEN buffer $(25 \mathrm{mM}$ Tris- $\mathrm{HCl}$, pH 7.5, 10\% (v/v) glycerol, $1 \mathrm{mM}$ EDTA, $150 \mathrm{mM} \mathrm{NaCl})$ supplemented with a protease inhibitor cocktail (Sigma), 0.1\% $(v / v)$ IGEPAL ${ }^{\circledR}$ CA-630 (Sigma), and $10 \mathrm{mM}$ DTT. Then, the agarose was washed 5 times with GTEN supplemented with $0.1 \%(v / v)$ IGEPAL $^{\circledR}$ CA-630 and the proteins were eluted by denaturation and heating.

\subsection{Protein Databases Searches, Alignment, and Phylogenetic Analysis}

Searches for A. thaliana PEPCs (AtPEPC1-4) were carried out with the NCBI database. The homolog sequences for $N$. benthamiana and homology index values were obtained using the BlastP server available for the draft sequence $N$. benthamiana genome database via the SOL Genomics Network from the Boyce Thompson Institute for Plant Research (https: //solgenomics.net/organism/Nicotiana_benthamiana/genome) [8]. Partial sequences were discarded. The selected PEPC protein sequences for $N$. benthamiana were named in terms of reference to their homology as follows: NbPPC1 (Niben101Scf25430g00015), NbPPC2 (Niben101Scf03628g14021), NbPPC3.1 (Niben101Scf00031g00003), NbPPC3.2 (Niben101Scf04036g04008), NbPPC3.3 (Niben101Scf03439g03004), and NbPPC4 (Niben101Scf00312g03005).

Alignments of the amino acid PEPCs sequences from N. benthamiana and A. thaliana were performed automatically using MUSCLE [64], implemented in MEGA version 10.0.5 [65]. Bayesian inference (BI) and maximum likelihood (ML) analyses were performed using MrBayes 3.2 [66] through the CIPRES science gateway [67] and RAxML 7.2.6 [68] through the T-Rex web server [69], respectively. Bayesian inference analysis was carried out as in [70], using the amino acid substitution model that best fit our data as predicted by ProtTest 3 [71], based on the highest Akaike's Information Criterion weights (AICw) [72]. In the case of the ML analysis, a PROTCAT model and Dayhoff matrix substitution model [73] were used. Bootstrap support (BS) values were calculated using a rapid bootstrapping algorithm with 10,000 rapid bootstrapping searches and 2000 ML searches to estimate the best tree. Bootstrap values under $70 \%$ were considered non-significant. Trees were finally edited using FigTree version 1.4.0 (http://tree.bio.ed.ac.uk/software/figtree/). Moreover, a pairwise evolutionary distance matrix was calculated with a gamma distribution of among-site rate variation as implemented in MEGA version 10.0.5 [64].

\subsection{Protein Digestion and Mass Spectrometry Identification}

Protein identification was accomplished by matrix-assisted laser desorption ionization time-of-flight mass spectrometry (MALDI-TOF-MS). Protein samples were analyzed by SDS-PAGE and stained with Coomassie Brilliant Blue R-250. Bands were excised with a cutting edge and de-stained afterwards using $25 \mathrm{mM}$ ammonium bicarbonate (AB) and acetonitrile. Disulfide bonds were reduced by embedding bands in $200 \mu \mathrm{L}$ of $10 \mathrm{mM}$ DTT 
and $50 \mathrm{mM} \mathrm{AB}$, which was maintained for $60 \mathrm{~min}$ at $56^{\circ} \mathrm{C}$. After reduction, the samples were incubated in $200 \mu \mathrm{L}$ of $30 \mathrm{mM}$ IAA and $50 \mathrm{mM} \mathrm{AB}$ for $30 \mathrm{~min}$ at room temperature in a dark environment in order to block Cys-SH groups.

Proteins were digested overnight at $37^{\circ} \mathrm{C}$ using trypsin bovine (Sequencing Grade Modified Trypsin, Promega) at a ratio of 1:10 for the enzyme and substrate, respectively. After digestion, acetonitrile and a trifluoroacetic acid $0.2 \%$ solution were added to the bands for peptide extraction. OMIX C18 tips (Agilent Technologies) were used for concentrating and desalting peptide extracts. Next, $0.5 \mu \mathrm{L}$ of each sample was spotted onto a MALDI sample plate. After solvent evaporation, $0.5 \mu \mathrm{L}$ alpha-cyano-hydroxycinnamic acid saturated solutions were spotted over the sample spots and air-dried.

MALDI fingerprint spectra were obtained using a MALDI-TOF Ultraflextreme (Bruker) system in the positive ion reflectron mode, summing 5000 shots for every spectrum. The FlexAnalysis software package was used to calibrate, select, and filter mass peaks. MS data were analyzed using the MASCOT search engine with the Biotools ${ }^{\mathrm{TM}}$ proteomic software package (Bruker) using static carbamidomethylation (C) and dynamic oxidation (M) modifications. Data were searched against the Uniprot $A$. thaliana and $N$. benthamiana protein database and against PEPC amino acid sequences. Peptides of interest were further analyzed by tandem mass spectrometry (MALDI TOF-MS/MS) in order to assess their sequences.

Supplementary Materials: The following are available online at https:/ / www.mdpi.com/2223-774 7/10/1/12/s1, Figure S1: Mascot peptide mass fingerprint analysis of the p110 band from tobacco cultured cells extract, Figure S2: Mascot peptide mass fingerprint analysis of the p100 band from tobacco cultured cells extract, Figure S3: Comparison of MALDI fingerprints of the p110 and p100 bands from tobacco cultured cells extract, Figure S4: Mascot peptide mass fingerprint analysis of the $63 \mathrm{kDa}$ band from the pull-down following transient expression of GFP-ATG8CL in N. benthamiana leaves, Table S1: Putative ATG8 interacting motifs (AIMs) in PEPC proteins identified with hfAIM.

Author Contributions: Conceptualization, S.G.-M., J.A.M., C.E., and G.B.; methodology, A.B.F., G.B., J.G., and L.H.-H.; formal analysis, J.G., S.G.-M., and J.A.M.; investigation, G.B., A.B.F., and L.H.-H.; writing-original draft preparation, S.G.-M. and G.B.; writing—review and editing, S.G.-M.; funding acquisition, S.G.-M., J.A.M., and C.E. All authors have read and agreed to the published version of the manuscript.

Funding: This research was funded by Junta de Andalucía (P12-FQM-489 and PAI group BIO298) and by Spanish Ministerio de Economía y Competitividad (AGL2012-35708 and AGL2016-75413-P).

Informed Consent Statement: Not applicable.

Data Availability Statement: The data presented in this study are available in article and supplementary material.

Acknowledgments: The authors thank Jean Vidal for the discussion of results and advice, and Enrique Maguilla for his help with the phylogenetic analysis. We also thank "Centro de Investigación, Tecnología e Innovación" (CITIUS) of the University of Seville and Ana Hortal (Servicio de Espectrometría de Masas Biomolecular BIO-MS, Pablo Olavide University) for providing technical assistance. The $\operatorname{atg} 2$ and atg5 lines were kindly provided by Yasin Dagdas (Gregor Mendel Institute of Molecular Plant Biology, Vienna, Austria).

Conflicts of Interest: The authors declare no conflict of interest.

\section{References}

1. Chollet, R.; Vidal, J.; O’Leary, M.H. Phosphoenolpyruvate carboxylase: A ubiquitous, highly regulated enzyme in plants. Annu. Rev. Plant. Physiol. Plant. Mol. Biol. 1996, 47, 273-298. [CrossRef] [PubMed]

2. O'Leary, B.; Park, J.; Plaxton, W.C. The remarkable diversity of plant PEPC (phosphoenolpyruvate carboxylase): Recent insights into the physiological functions and post-translational controls of non-photosynthetic PEPCs. Biochem. J. 2011, 436, 15-34. [CrossRef] [PubMed]

3. Nimmo, H.G. The regulation of PEPC in CAM plants. Trends Plant. Sci. 2000, 5, 75-80. [CrossRef]

4. Paterson, A.H.; Bowers, J.E.; Bruggmann, R.; Dubchak, I.; Grimwood, J.; Gundlach, H.; Haberer, G.; Hellsten, U.; Mitros, T.; Poliakov, A.; et al. The Sorghum bicolor genome and the diversification of grasses. Nature 2009, 457, 551-556. [CrossRef] 
5. Sánchez, R.; Cejudo, F.J. Identification and expression analysis of a gene encoding a bacterial-type phosphoenolpyruvate carboxylase from Arabidopsis and rice. Plant Physiol. 2003, 132, 949-957. [CrossRef] [PubMed]

6. Shi, J.; Yi, K.; Liu, Y.; Xie, L.; Zhou, Z.; Chen, Y.; Hu, Z.; Zheng, T.; Liu, R.; Chen, Y.; et al. Phosphoenolpyruvate carboxylase in Arabidopsis leaves plays a crucial role in carbon and nitrogen metabolism. Plant Physiol. 2015, 167, 671-681. [CrossRef]

7. Sánchez, R.; Flores, A.; Cejudo, F.J. Arabidopsis phosphoenolpyruvate carboxylase genes encode immunologically unrelated polypeptides and are differentially expressed in response to drought and salt stress. Planta 2006, 223, 901-909. [CrossRef]

8. Bombarely, A.; Rosli, H.G.; Vrebalov, J.; Moffett, P.; Mueller, L.A.; Martin, G.B. A draft genome sequence of Nicotiana benthamiana to enhance molecular plant-microbe biology research. Mol. Plant Microbe Interact. 2012, 25, 1523-1530. [CrossRef]

9. Echevarría, C.; Vidal, J. The unique phosphoenolpyruvate carboxylase kinase. Plant Physiol. Biochem. 2003, 41, 541-547. [CrossRef]

10. Ruiz-Ballesta, I.; Feria, A.B.; Ni, H.; She, Y.M.; Plaxton, W.C.; Echevarría, C. In Vivo monoubiquitination of anaplerotic phosphoenolpyruvate carboxylase occurs at Lys624 in germinating sorghum seeds. J. Exp. Bot. 2014, 65, 443-451. [CrossRef]

11. Ruiz-Ballesta, I.; Baena, G.; Gandullo, J.; Wang, L.; She, Y.M.; Plaxton, W.C.; Echevarría, C. New insights into the post-translational modification of multiple phosphoenolpyruvate carboxylase isoenzymes by phosphorylation and monoubiquitination during sorghum seed development and germination. J. Exp. Bot. 2016, 67, 3523-3536. [CrossRef] [PubMed]

12. Arias-Baldrich, C.; de la Osa, C.; Bosch, N.; Ruiz-Ballesta, I.; Monreal, J.A.; García-Mauriño, S. Enzymatic activity, gene expression and posttranslational modifications of photosynthetic and non-photosynthetic phosphoenolpyruvate carboxylase in ammoniumstressed sorghum plants. J. Plant Physiol. 2017, 214, 39-47. [CrossRef] [PubMed]

13. Baena, G.; Feria, A.B.; Echevarría, C.; Monreal, J.A.; García-Mauriño, S. Salinity promotes opposite patterns of carbonylation and nitrosylation of $C_{4}$ phosphoenolpyruvate carboxylase in sorghum leaves. Planta 2017, 246, 1203-1214. [CrossRef] [PubMed]

14. Uhrig, R.G.; Schläpfer, P.; Roschitzki, B.; Hirsch-Hoffmann, M.; Gruissem, W. Diurnal changes in concerted plant protein phosphorylation and acetylation in Arabidopsis organs and seedlings. Plant J. 2019, 99, 176-194. [CrossRef] [PubMed]

15. Echevarría, C.; Vidal, J.; Jiao, J.A.; Chollet, R. Reversible light activation of phosphoenolpyruvate carboxylase protein-serine kinase in maize leaves. FEBS Lett. 1990, 275, 25-28. [CrossRef]

16. Boxall, S.F.; Dever, L.V.; Knrová, J.; Gould, P.D.; Hartwell, J. Phosphorylation of phosphoenolpyruvate carboxylase is essential for maximal and sustained dark $\mathrm{CO}_{2}$ fixation and core circadian clock operation in the obligate Crassulacean Acid Metabolism species Kalanchoë fedtschenkoi. Plant Cell 2017, 29, 2519-2536. [CrossRef]

17. Pickart, C.; Eddins, M. Ubiquitin: Structures, functions, mechanisms. Biochim. Biophys. Acta 2004, 1695, 55-72. [CrossRef]

18. Uhrig, R.G.; She, Y.M.; Leach, C.A.; Plaxton, W.C. Regulatory monoubiquitination of phosphoenolpyruvate carboxylase in germinating castor oil seeds. J. Biol. Chem. 2008, 283, 29650-29657. [CrossRef]

19. Shane, M.W.; Fedosejevs, E.T.; Plaxton, W.C. Reciprocal control of anaplerotic phosphoenolpyruvate carboxylase by in vivo monoubiquitination and phosphorylation in developing proteoid roots of phosphate deficient harsh hakea. Plant Physiol. 2013, 161, 1634-1644. [CrossRef]

20. Figueroa, C.; Feil, R.; Ishihara, H.; Watanabe, M.; Kölling, K.; Krause, U.; Höhne, M.; Encke, B.; Plaxton, W.C.; Zeeman, S.C.; et al. Trehalose 6-phosphate coordinates organic and amino acid metabolism with carbon availability. Plant J. 2016, 85, 410-423. [CrossRef]

21. Bassham, D.C. Plant autophagy-more than starvation response. Curr. Opin. Plant Biol. 2007, 10, 587-593. [CrossRef] [PubMed]

22. Mizushima, N.; Yoshimori, T.; Ohsumi, Y. The role of ATG proteins in autophagosome formation. Annu. Rev. Cell. Dev. Biol. 2011, 27, 107-312. [CrossRef] [PubMed]

23. Bassham, D.C.; Laporte, M.; Marty, F.; Moriyasu, Y.; Ohsumi, Y.; Olsen, L.J.; Yoshimoto, K. Autophagy in development and stress responses of plants. Autophagy 2006, 2, 2-11. [CrossRef] [PubMed]

24. Han, S.; Yu, B.; Wang, Y.; Liu, Y. Role of plant autophagy in stress response. Protein Cell 2011, 2, 784-791. [CrossRef]

25. Ren, C.; Liu, J.; Gong, Q. Functions of autophagy in plant carbon and nitrogen metabolism. Front. Plant Sci. 2014, 5, 301. [CrossRef]

26. Masclaux-Daubresse, C.; Chen, Q.; Havé, M. Regulation of nutrient recycling via autophagy. Curr. Opin. Plant Biol. 2017, 39, 8-17. [CrossRef]

27. Marshall, R.S.; Vierstra, R.D. Autophagy: The master of bulk and selective recycling. Annu. Rev. Plant. Biol. 2018, 69, 173-208. [CrossRef]

28. Guiboileau, A.; Yoshimoto, K.; Soulay, F.; Bataillé, M.; Avice, J.C.; Masclaux-Daubresse, C. Autophagy machinery controls nitrogen remobilization at the whole-plant level under both limiting and ample nitrate conditions in Arabidopsis. New Phytol. 2012, 194, 732-740. [CrossRef]

29. Li, F.; Chung, T.; Pennington, J.G.; Federico, M.L.; Kaeppler, H.F.; Kaeppler, S.M.; Otegui, M.S.; Vierstra, R.D. Autophagic recycling plays a central role in maize nitrogen remobilization. Plant Cell 2015, 27, 1389-1408. [CrossRef]

30. Chen, Q.; Soulay, F.; Saudemont, B.; Elmayan, T.; Marmagne, A.; Masclaux-Daubresse, C. Overexpression of ATG8 in Arabidopsis stimulates autophagic activity and increases nitrogen remobilization efficiency and grain filling. Plant Cell Physiol. 2019, 60, 343-352. [CrossRef]

31. Yu, J.; Zhen, X.; Li, X.; Li, N.; Xu, F. Increased autophagy of rice can increase yield and nitrogen use efficiency (NUE). Front. Plant Sci. 2019, 10, 584. [CrossRef]

32. Wang, P.; Mugume, Y.; Bassham, D.C. New advances in autophagy in plants: Regulation, selectivity and function. Semin. Cell. Dev. Biol. 2018, 80, 113-122. [CrossRef] 
33. Avin-Wittenberg, T.; Honig, A.; Galili, G. Variations on a theme, plant autophagy in comparison to yeast and mammals. Protoplasma 2012, 249, 285-299. [CrossRef] [PubMed]

34. Xia, K.F.; Liu, T.; Ouyang, J.; Wang, R.; Fan, T.; Zhang, M.Y. Genome-wide identification, classification, and expression analysis of autophagy-associated gene homologues in rice (Oryza sativa L.). DNA Res. 2011, 18, 363-377. [CrossRef]

35. Kellner, R.; De la Concepcion, J.C.; Maqbool, A.; Kamoun, S.; Dagdas, Y.F. ATG8 expansion: A driver of selective autophagy diversification? Trends Plant Sci. 2017, 22, 204-214. [CrossRef] [PubMed]

36. Kalvari, I.; Tsompanis, S.; Mulakkal, N.C.; Osgood, R.; Johansen, T.; Nezis, I.P.; Promponas, V.J. iLIR. Autophagy 2014, 10, 913-925. [CrossRef]

37. Xie, Q.; Tzfadia, O.; Levy, M.; Weithorn, E.; Peled-Zehavi, H.; Van Parys, T.; Vande Peer, Y.; Galili, G. HfAIM: A reliable bioinformatics approach for in silico genome-wide identification of autophagy-associated Atg8-interacting motifs in various organisms. Autophagy 2016, 12, 876-887. [CrossRef] [PubMed]

38. Marshall, R.S.; Hua, Z.; Mali, S.; McLoughlin, F.; Vierstra, R.D. ATG8-binding UIM proteins define a new class of autophagy adaptors and receptors. Cell 2019, 177, 766-781. [CrossRef] [PubMed]

39. Svenning, S.; Lamark, T.; Krause, K.; Johansen, T. Plant NBR1 is a selective autophagy substrate and a functional hybrid of the mammalian autophagic adapters NBR1 and p62/SQSTM1. Autophagy 2011, 7, 993-1010. [CrossRef] [PubMed]

40. Zientara-Rytter, K.; Lukomska, J.; Moniuszko, G.; Gwozdecki, R.; Surowiecki, P.; Lewandowska, M.; Liszewska, F.; Wawrzynska, A.; Sirko, A. Identification and functional analysis of Joka2, a tobacco member of the family of selective autophagy cargo receptors. Autophagy 2011, 7, 1145-1158. [CrossRef]

41. Sarkar, S.; Davies, J.E.; Huang, Z.; Tunnacliffe, A.; Rubinsztein, D.C. Trehalose, a novel mTOR-independent autophagy enhancer, accelerates the clearance of mutant huntingtin and $\alpha$-synuclein. J. Biol. Chem. 2007, 282, 5641-5652. [CrossRef] [PubMed]

42. Zhang, X.; Chen, S.; Song, L.; Tang, Y.; Shen, Y.; Jia, L. MTOR-independent, autophagic enhancer trehalose prolongs motor neuron survival and ameliorates the autophagic flux defect in a mouse model of amyotrophic lateral sclerosis. Autophagy 2014, 10, 588-602. [CrossRef] [PubMed]

43. Williams, B.; Njaci, I.; Moghaddam, L.; Long, H.; Dickman, M.B.; Zhang, X.; Mundree, S. Trehalose accumulation triggers autophagy during plant desiccation. PLoS Genet. 2015, 11, e1005705. [CrossRef] [PubMed]

44. Xiong, Y.; Contento, A.L.; Bassham, D.C. AtATG18a is required for the formation of autophagosomes during nutrient stress and senescence in Arabidopsis thaliana. Plant J. 2005, 42, 535-546. [CrossRef] [PubMed]

45. Schreiber, A.; Peter, M. Substrate recognition in selective autophagy and the ubiquitin-proteasome system. Biochim. Biophys. Acta 2014, 1843, 163-181. [CrossRef] [PubMed]

46. Seglen, P.O.; Gordon, P.B. 3-methyladenine: Specific inhibitor of autophagic/lysosomal protein degradation in isolated rat hepatocytes. Proc. Natl. Acad. Sci. USA 1982, 79, 1889-1892. [CrossRef]

47. Matsuoka, K.; Higuchi, T.; Maeshima, M.; Nakamura, K. A vacuolar-type $\mathrm{H}^{+}$-ATPase in a nonvacuolar organelle is required for the sorting of soluble vacuolar protein precursors in tobacco cells. Plant Cell 1997, 9, 533-546. [CrossRef]

48. Takatsuka, C.; Inoue, Y.; Higuchi, T.; Hillmer, S.; Robinson, D.G.; Moriyasu, Y. Autophagy in tobacco BY-2 cells cultured under sucrose starvation conditions: Isolation of the autolysosome and its characterization. Plant Cell Physiol. 2011, 52, 2074-2087. [CrossRef]

49. Finley, D. Recognition and processing of ubiquitin-protein conjugates by the proteasome. Annu. Rev. Biochem. 2009, 78, 477-513. [CrossRef]

50. Yoshimoto, K.; Hanaoka, H.; Sato, S.; Kato, T.; Tabata, S.; Noda, T.; Ohsumi, Y. Processing of ATG8s, ubiquitin-like proteins, and their deconjugation by ATG4s are essential for plant autophagy. Plant Cell 2004, 16, 2967-2983. [CrossRef]

51. Osuna, L.; Pierre, J.N.; González, M.C.; Alvarez, R.; Cejudo, F.J.; EchevarrPa, C.; Vidal, J. Evidence for a slow-turnover form of the $\mathrm{Ca}_{2}{ }^{+}$-independent phosphoenolpyruvate carboxylase kinase in the aleurone-endosperm tissue of germinating barley seeds. Plant Physiol. 1999, 119, 511-520. [CrossRef] [PubMed]

52. Feria, A.B.; Bosch, N.; Sánchez, A.; Nieto-Ingelmo, A.I.; de la Osa, C.; Echevarría, C.; García-Mauriño, S.; Monreal, J.A. Phosphoenolpyruvate carboxylase (PEPC) and PEPC-kinase (PEPC-k) isoenzymes in Arabidopsis thaliana: Role in control and abiotic stress conditions. Planta 2016, 244, 901-913. [CrossRef] [PubMed]

53. Sage, R.S. Photosynthetic efficiency and carbon concentration in terrestrial plants: The $\mathrm{C}_{4}$ and CAM solutions. J. Exp. Bot. 2014, 65, 3323-3325. [CrossRef] [PubMed]

54. Begum, H.; Osaki, M.; Watanabe, T.; Shinano, T. Mechanisms of aluminum tolerance in phosphoenolpyruvate carboxylase transgenic rice. J. Plant Nutr. 2009, 32, 84-96. [CrossRef]

55. Willick, I.R.; Plaxton, W.C.; Lolle, S.J.; Macfie, S.M. Transcriptional and post-translational upregulation of phosphoenolpyruvate carboxylase in Arabidopsis thaliana (L. Heynh) under cadmium stress. Environ. Exp. Bot. 2019, 164, 29-39. [CrossRef]

56. Monreal, J.A.; Arias-Baldrich, C.; Pérez-Montaño, F.; Gandullo, J.; Echevarría, C.; García-Mauriño, S. Factors involved in the rise of phosphoenolpyruvate carboxylase-kinase activity caused by salinity in sorghum leaves. Planta 2013, 237, 1401-1413. [CrossRef]

57. Schulz, M.; Klockenbring, T.; Hunte, C.; Schnabl, H. Involvement of ubiquitin in phosphoenolpyruvate carboxylase degradation. Bot. Acta 1993, 106, 143-145. [CrossRef]

58. Agetsuma, M.; Furumoto, T.; Yanagisawa, S.; Izui, K. The ubiquitin-proteasome pathway is involved in rapid degradation of phosphoenolpyruvate carboxylase kinase for $\mathrm{C}_{4}$ photosynthesis. Plant Cell Physiol. 2005, 46, 389-398. [CrossRef] 
59. Wang, Y.; Nishimura, M.T.; Zhao, T.; Tang, D. ATG2, an autophagy-related protein, negatively affects powdery mildew resistance and mildew-induced cell death in Arabidopsis. Plant J. 2011, 68, 74-87. [CrossRef]

60. McLoughlin, F.; Augustine, R.C.; Marshall, R.S.; Li, F.; Kirkpatrick, L.D.; Otegui, M.S.; Vierstra, R.D. Maize multi-omics reveal roles for autophagic recycling in proteome remodelling and lipid turnover. Nat. Plants 2018, 4, 1056-1070. [CrossRef]

61. Gandullo, J.; Monreal, J.A.; Álvarez, R.; Díaz, I.; García-Mauriño, S.; Echevarría, C. Anionic phospholipids induce conformational changes in phosphoenolpyruvate carboxylase to increase sensitivity to cathepsin proteases. Front. Plant Sci. 2019, 10, 582. [CrossRef] [PubMed]

62. Echevarría, C.; Pacquit, V.; Bakrim, N.; Osuna, L.; Delgado, B.; Arrio-Dupont, M.; Vidal, J. The effect of pH on the covalent and metabolic controls of $\mathrm{C}_{4}$ phosphoenolpyruvate carboxylase from Sorghum leaf. Arch. Biochem. Biophys. 1994, 315, 425-430. [CrossRef] [PubMed]

63. Pacquit, V.; Giglioli, N.; Crétin, C.; Pierre, J.N.; Vidal, J.; Echevarría, C. Regulatory phosphorylation of $\mathrm{C}_{4}$ phosphoenolpyruvate carboxylase from Sorghum. An immunological study using specific anti-phosphorylation site antibodies. Photosynth. Res. 1995, 43, 283-288. [CrossRef] [PubMed]

64. Edgar, R.C. Muscle: A multiple sequence alignment method with reduced time and space complexity. Biomed. Cent. Bioinform. 2004, 5, 113. [CrossRef]

65. Kumar, S.; Stecher, G.; Li, M.; Knyaz, C.; Tamura, K. Mega X: Molecular evolutionary genetics anaysis across computing platforms. Mol. Biol. Evol. 2018, 35, 1547-1549. [CrossRef]

66. Ronquist, F.; Teslenko, M.; van der Mark, P.; Ayres, D.L.; Darling, A.; Hohna, S.; Larget, B.; Liu, L.; Suchard, M.A.; Huelsenbeck, J.P. MrBayes 3.2: Efficient Bayesian phylogenetic inference and model choice across a large model space. Syst. Biol. 2012, 61, 539-542. [CrossRef]

67. Miller, M.; Holder, M.; Vos, R.P.; Midford, P.; Liebowitz, T.; Chan, L.; Hoover, P.; Warnow, T. The CIPRES Portals. 2009. Available online: http:/ /www.phylo.org/portal2/ (accessed on 15 October 2019).

68. Stamatakis, A. RA $\times$ ML-VI-HPC: Maximum likelihood-based phylogenetic analyses with thousands of taxa and mixed models. Bioinformatics 2006, 22, 2688-2690. [CrossRef]

69. Boc, A.; Diallo, A.B.; Makarenkov, V. T-Rex: A web server for inferring, validating and visualizing phylogenetic trees and networks. Nucleic Acids Res. 2012, 40, W573-W579. [CrossRef]

70. Maguilla, E.; Escudero, M.; Waterway, M.J.; Hipp, A.L.; Luceño, M. Phylogeny, systematics, and trait evolution of Carex section Glareosae. Am. J. Bot. 2015, 102, 1128-1144. [CrossRef]

71. Darriba, D.; Taboada, G.L.; Doallo, R.; Posada, D. ProtTest 3: Fast selection of best-fit models of protein evolution. Bioinformatics 2011, 27, 1164-1165. [CrossRef]

72. Akaike, H. A new look at the statistical model identification. IEEE Trans. Autom. Control. 1974, 19, 716-723. [CrossRef]

73. Dayhoff, M.; Schwartz, R.; Orcutt, B. A model of evolutionary change in proteins. In Atlas of Protein Sequence and Structure; Dayhoff, M., Ed.; National Biomedical Research Foundation: Washington, DC, USA, 1978; Volume 5, pp. $345-352$. 